\title{
EVALUATION OF DYNAMIC GROUND CHARACTERISTICS AND SEISMIC MICROZONING
}

\author{
Yoshikazu Kitagawa* and Yutaka Matsushima** \\ Presented at the Third South Pacific Regional Conference on \\ Earthquake Engineering, Wellington, May 1983.
}

\section{SYNOPSIS:}

The maximum earthquake motions on the ground, the dynamic characteristics of soil-layers in the range of short period reflecting the shallow soil-layers on a small area are investigated, taking Sendai district damaged by the off-Miyagi Prefecture Earthquake of June, 1978 as an example. The modeling of ground characteristics is performed based on the results of the analytical investigation of the elastic and inelastic system as well as microtremor measurements, boring data and penetration tests.

In order to establish an appropriate seismic microzoning method with particular attention to the mathematical modeling, the predominant periods, magnification factors, maximum accelerations and velocities on the ground surface and the ductility factors of super-structure are computed. The correlation between such seismic microzoning maps and the extent of real damage to buildings is satisfactory.

\section{INTRODUCTION :}

It is one of the most important problems in the field of earthquake engineering to predict the maximum earthquake motions in a certain place which may be defined by the seismic activity and ground characteristics. In order to clarify this more reliably, it is necessary to investigate each of them separately. Generally the ground motion in the frequency domain ( $(j w)$ ) will be expressed by the following equation,

$G(j w)=(F S(j w) \cdot T F(j w)) \cdot S T(j w) \ldots \ldots$

where FS $(j w), T F(j w)$ and $S T(j w)$ represent the spectrum of the focal mechanism, the overall transmission function for the generation and propagation of earthquake waves, and the function for the wave propagation of local soil layers, respectively. The former part in parentheses of the equation stands for the theoretical seismic records based on the focal mechanism, and the latter for the ground motion dealt with in the earthquake engineering.

It is pointed out that the long period ( $1.0<T \leqslant 10$ sec.) corresponding to the ground characteristics of fairly large area is amplified by soil-layers with the depth varying from a few hundred meters to $1-2$ Kilometers, and that the short period ( $T \leqslant 1.0$ sec.) corresponding to the ground characteristics just beneath a construction is affected by soil-layers with the depth less than a few hundred meters. The former corresponds to the seismic

* Head of Structural Dynamics Division, Building Research Institute, Ministry of Construction, Japanese Government

* * Associate Professor, Institute of Engineering Mechanics, University of Tsukuba, Japan macrozoning and the latter to the seismic microzoning. For the Jatter category, the structural base rock with the shear wave velocity of $700 \mathrm{~m} / \mathrm{sec}$. is set up in this study.

The evaluation of ground characteristics in the range of short periods is performed based on the results of the analytical investigation of the elastic system with damping which is independent of frequency as well as of microtremor measurements. The various seismic microzoning maps thus obtained are compared with the distribution of real damages to buildings.

\section{OUTLINE OF GEOLOGICAL CONDITION:}

Topographical Aspects - As for the geological conditions of surface soil, the Sendai district is generally classified into three areas as shown in Fig. 1; (1) the hilly tertiary terrain, (2) the terrace area and (3) the alluvial plain. The oblique NE-SW line passing near the center of the map is called the RifuNagamachi tectonic line. The area in the west of the tectonic line is characterized by the hilly tertiary terrain and the several levels of terraces. The surface deposit of this terrace is loam which is underlain by hard clay, gravels, pelite and shale. The hilly terrain is either of very hard andesite and shale. but the surface is covered with loam at several places. The alluvial plain develops in the east of this line and is mostly of sand, silt and gravels.

The depth of the tertiary base rock varies abruptly near the tectonic line. There are several areas in the plain which are covered by very soft peat or mud. The soil profile and the results of seismic prospecting tests by the well shooting method at representative places in the terrace area and the alluvial area are shown in Fig. 2 . 


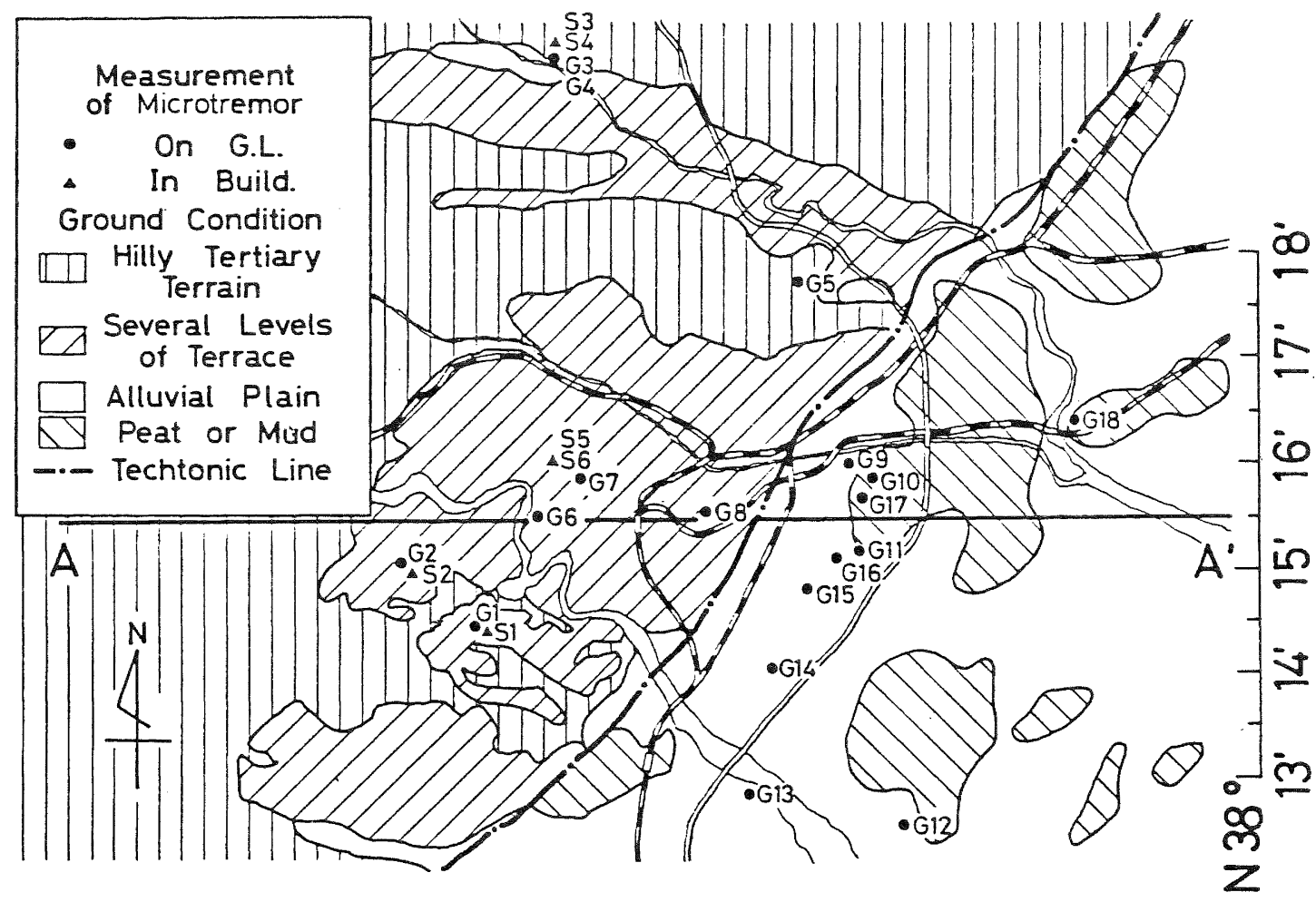

Fig。 1 Geological Condition
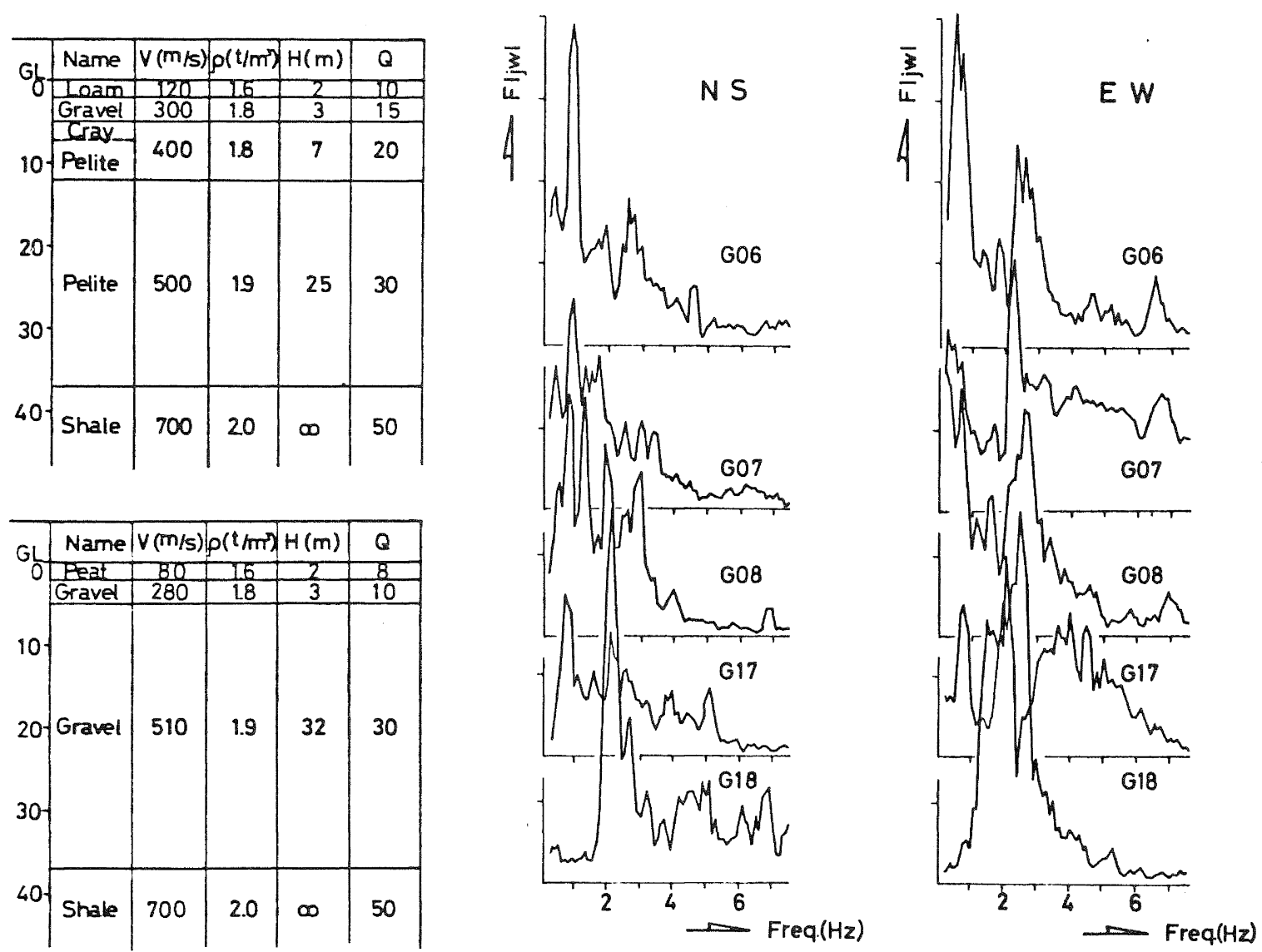

Fig。 2 Profile of Subsoil

Fig. 3 Fourier Spectra of Microtremor 
Microtremor Measurements - The microtremors are measured at several sites shown in Fig. I with electromagnetic seismometer having the natural period of $1.0 \mathrm{sec}$. to get dynamic properties of soil-layers. ${ }^{1}$ ) The area where the measurements were performed belongs to two types of geological conditions (2) and (3) mentioned above.

The representative Fourier spectra of microtremors in NS and EW directions are shown in Fig. 3, where sites G-06 through $G-08$ and sites $G-17$ and $G-18$ are on the outcrop of terrace and on the alluvial plain, respectively. The peaks at long periods more than $1.0 \mathrm{sec}$. reflect the deep ground characteristics, whereas the peaks at short periods less than $1.0 \mathrm{sec}$. are due to the shallow ground sites.

Setting up Structural Base Rock - The function, which is defined by the ratio of the wave on the ground surface (Uo) to the incident wave (Uin), for the deep underground structure and for the shallow one at a representative place in the terrace near the sendai station of J.M.A. are shown in Fig. 4. The shear wave velocities $V$ and densities $\rho$ of the various soil-layers were determined by the seismic prospecting test, the seismic data of strong motion seismographs of J.M.A. and the boring tests.

As seen in Fig. 4, there are some peaks depending on the levels of the base rock but the predominant frequency between 3.0 and $4.0 \mathrm{~Hz}$ is common to both. This frequency also appears in the results obtained by microtremor measurements at the sites G-06 through G-08.

Consequently in this study, the structural base rock with shear wave velocity of $700 \mathrm{~m} / \mathrm{sec}$. is set up to get the ground characteristics in the range of short periods less than $1.0 \mathrm{sec}$. The values of shear wave velocity at intervals of $0.5^{\prime}$ in both Latitude and Longitude in the Sendai district are estimated from the soil profile, results of the penetration tests and the geological conditions. 2 Fig. 5 displays the profile of shear wave velocity on each section (from line of $\mathrm{N} 38^{\circ} 13^{\prime} 30^{\prime \prime}$ to $\mathrm{N} 38^{\circ} 17^{\prime}$ ) as indicated in Fig. 1 .

\section{SEISMIC MICROZONING :}

\section{Incident Wave Motions in the Structural Base Rock -}

In order to estimate the earthquake motions on the ground surface, the strong motions gbserved at the sendai sumitomo Building ${ }^{3}$ during the Off-Miyagi Prefecture Earthquake of June, $1978 \quad(M=7.4)$ were analyzed with consideration of buildingsubsoil interaction to get the incident wave at the structural base rock with shear wave velocity of $700 \mathrm{~m} / \mathrm{sec}$. The building is an eighteen-storied steel framed reinforced concrete structure with two-storied basements. The plan and elevation of this building are shown in Fig. 6 where the locations of strong motion accelerographs are indicated. Figure 7 shows the accelerograms recorded at the 2nd basement floor and the 18 th floor.

The building and subsoil were idealized as an elastic one-dimensional continuous media with some amount of damping which is independent of frequency. The parameters required in the analysis were determined based on the results of these Fourier spectra for the accelerograms at the $18 \mathrm{th}$ floor and the 2 nd basement floor together with seismic prospecting. The rigidities and densities for the layers representing the building and the first soil layer were modified so as to approximately satisfy the compatibility at the boundary, assuming that shear waves are propagated and reflected only in the vertical direction.

Figure 8 shows the observed and the calculated maximum accelerations in NS and EW directions together with the assumed shear wave velocities of this particular site. Figures $9(\mathrm{a})$ and $(\mathrm{b})$ indicate the response acceleration spectra with damping ratio (h) of 0.05 for the observed wave at the 2 nd basement floor, the calculated incident wave at structural base rock, and the calculated wave at outcropping of the 2 nd basement floor level in NS and EW directions.

Using the two components thus obtained at the base rock, a wave form for the major principal axis ${ }^{5}$ was calculated, which was taken as the final incident wave. The direction of its axis was N18. $5^{\circ} \mathrm{E}$ in two-dimensional space. Figure 10 shows the resultant incident wave motion at the structural base rock.

Response Analysis of Soil-layers - Two kinds of response analyses such as elastic and inelastic ones were carried out for soil-layers. In the latter case, the Ramberg-Osgood hysteresis is asssumed for the restoring force characteristics of soil deposits. 6 In both cases, soillayers are idealized as a lumped massspring system having an additional damper at the base rock.

Figure 11 shows the vertical distributions of maximum acceleration and shear strain in a certain site having soft soil-layers, as an example. It is recognized that the results of the elastic analysis fairly differ from those of the inelastic one. Fourier spectra for the surface motions in these two cases are shown in Fig. 12. The clear difference between frequency contents of the two motions can be found.

\section{Distribution of Dynamic Characteristics for Underground Structure -}

The predominant period and magnification factor of the elastic media are calculated at an interval of $0.5^{\prime}$ in both Latitude and Longitude by the Haskell's Method. The distribution maps for the predominant period and magnification factor of the underground structure above the structural base rock are shown in Figs. 13 and 14, respectively. As found from these figures, the predominant period is around $0.2-0.3 \mathrm{sec}$. in the terrace area and $0.3-0.8 \mathrm{sec}$. in the 


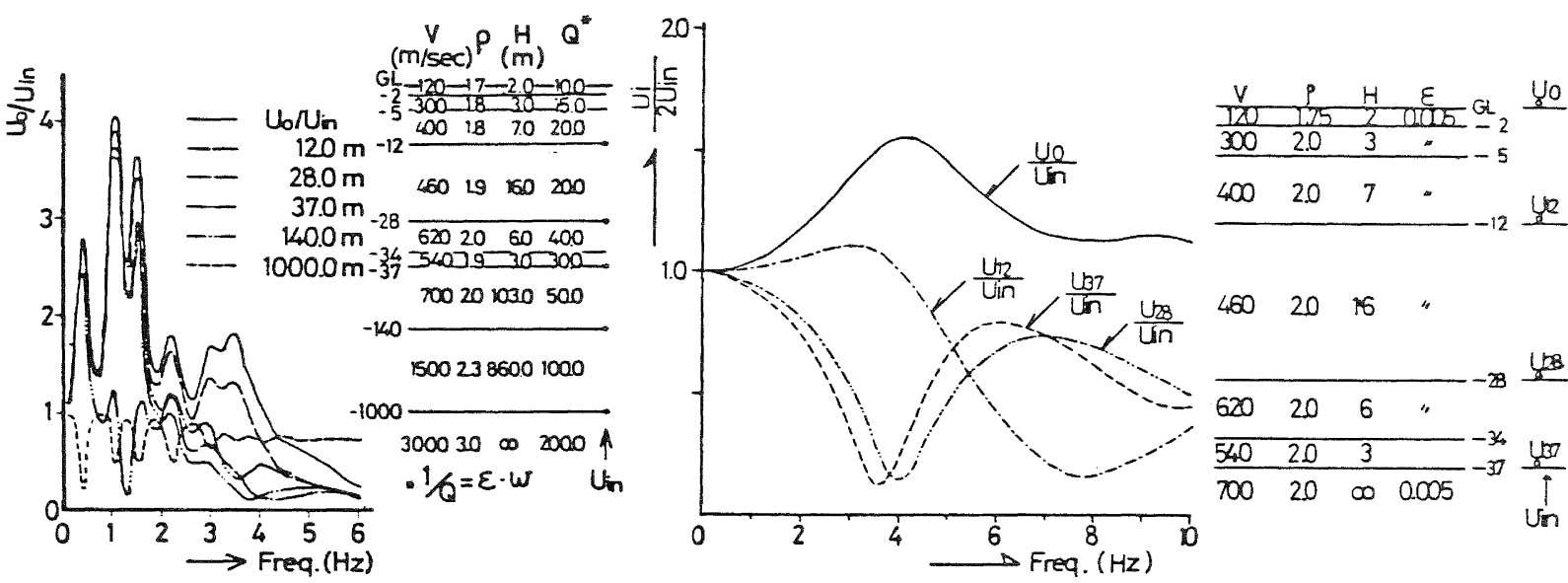

Fig. 4 Transfer Function of Soil-layers
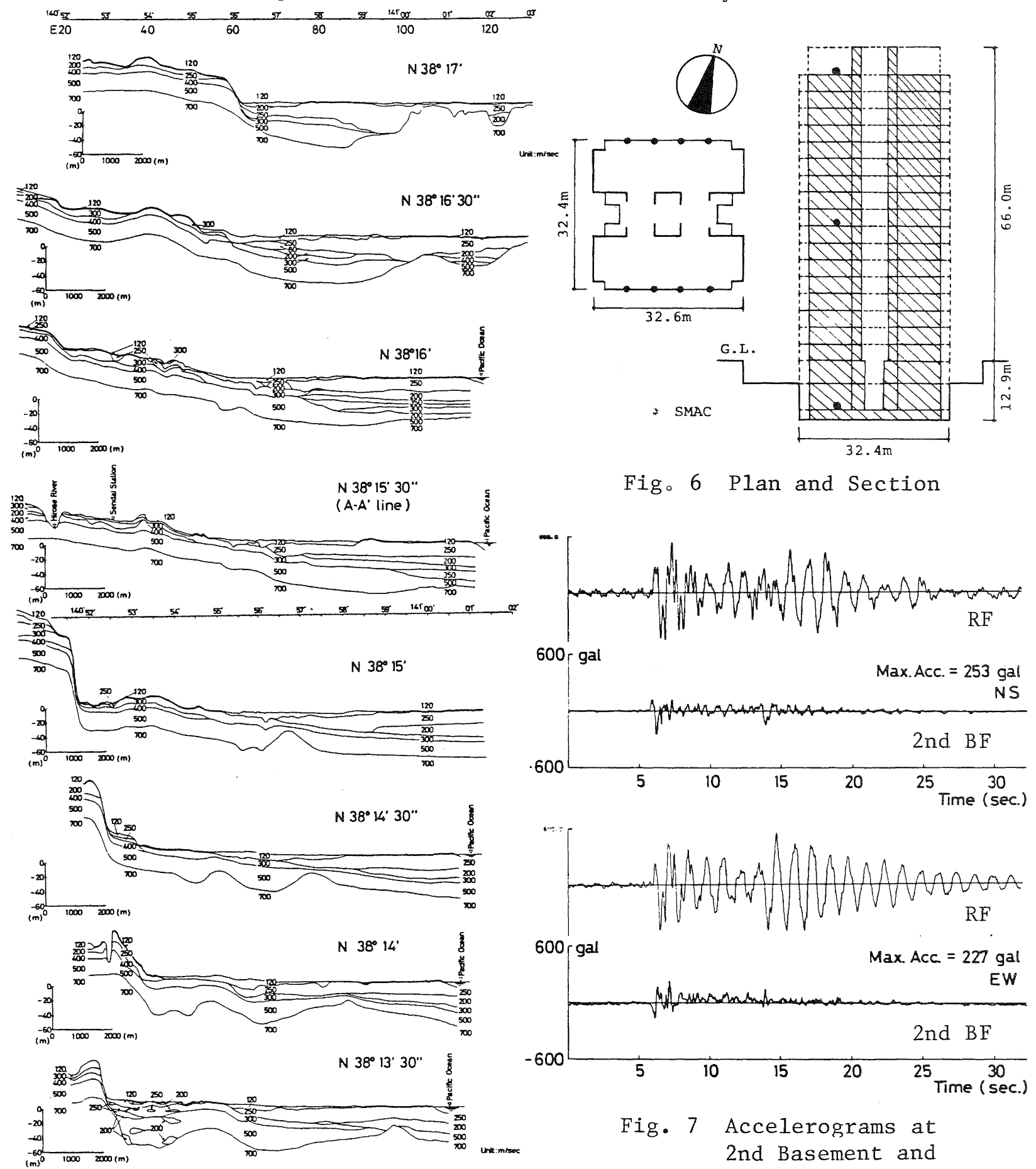

Fig. 7 Accelerograms at 2nd Basement and

Fig. 5 Profile of Shear Wave Velocity 18th Floor 


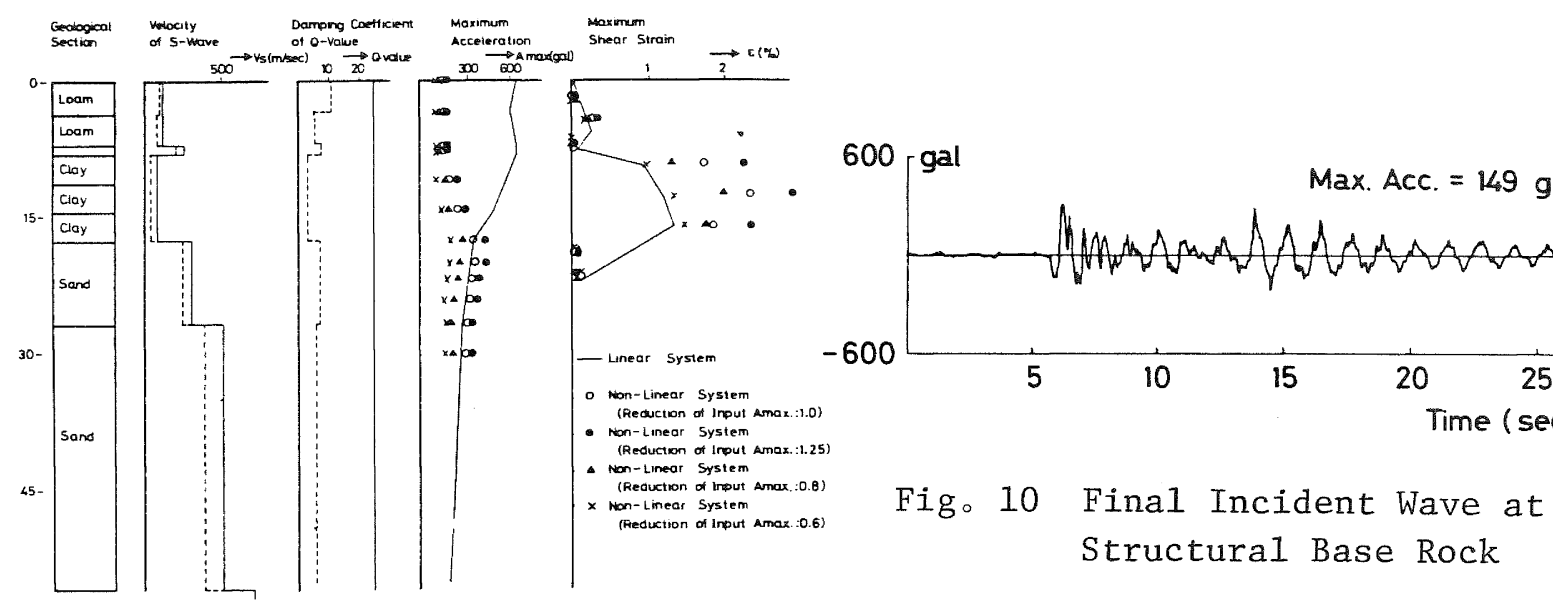

Fig. 8 Max. Acceleration Values
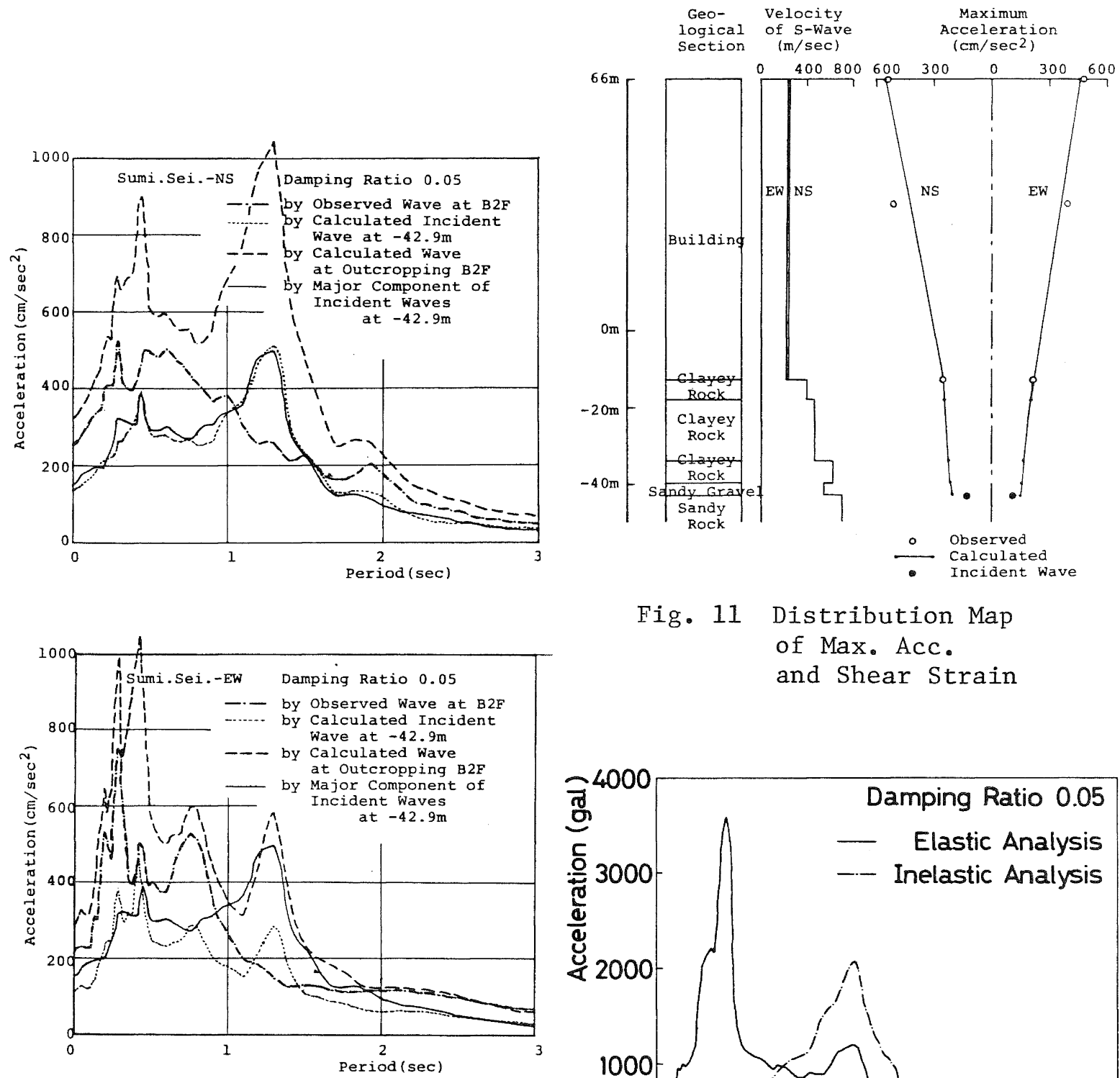

Fig. 11 Distribution Map of Max. Acc. and Shear Strain

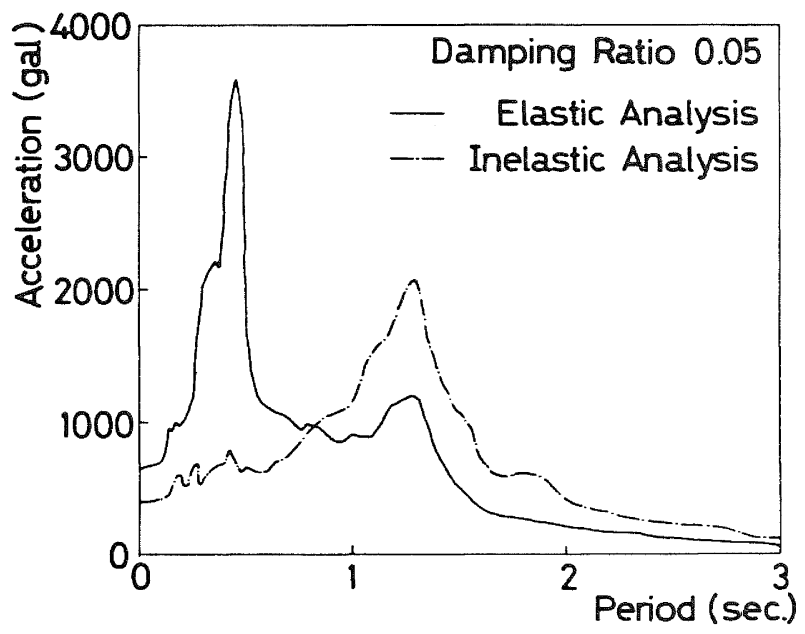

Fig. 12 Response Spectra of Calculated Wave 


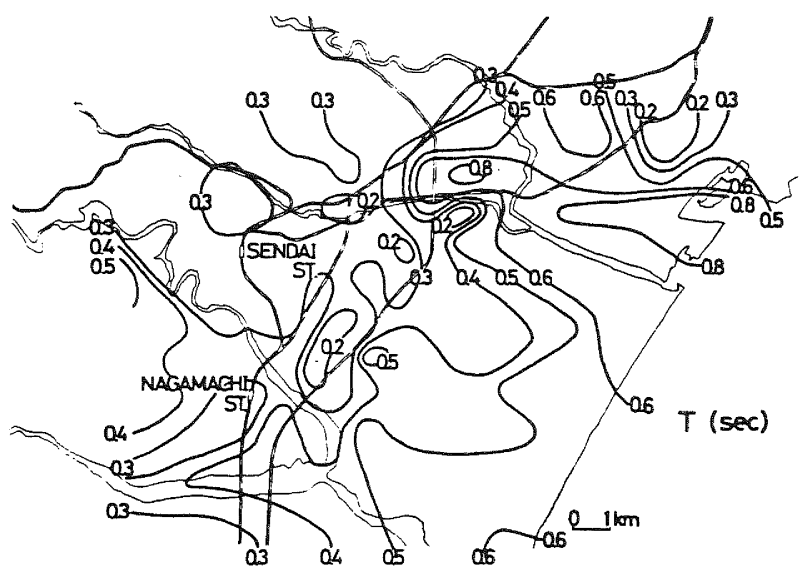

Fig. 13 Distribution Map of Predominant Period

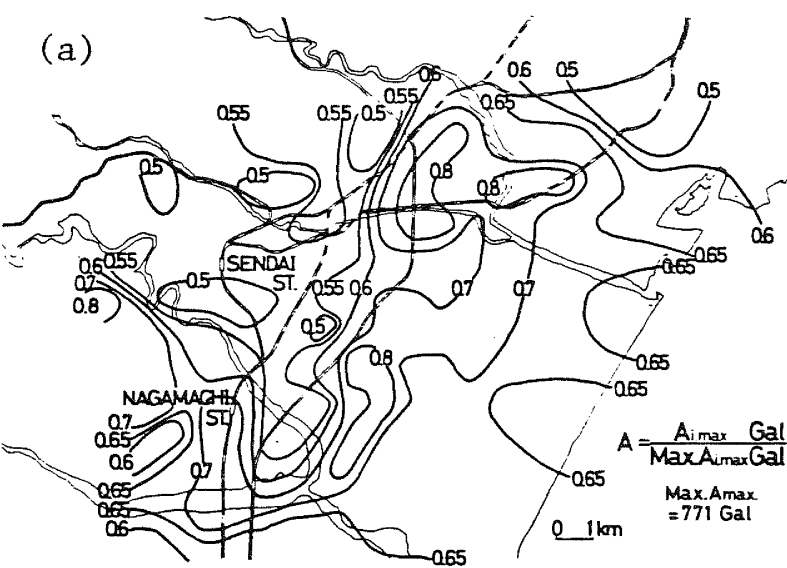

(b)

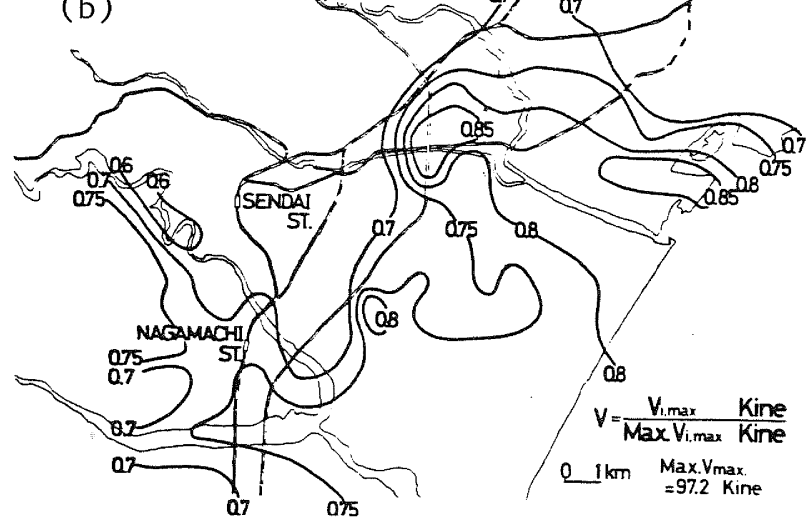

Fig. 15 Distribution Map of Max。 Acceleration and Velocity

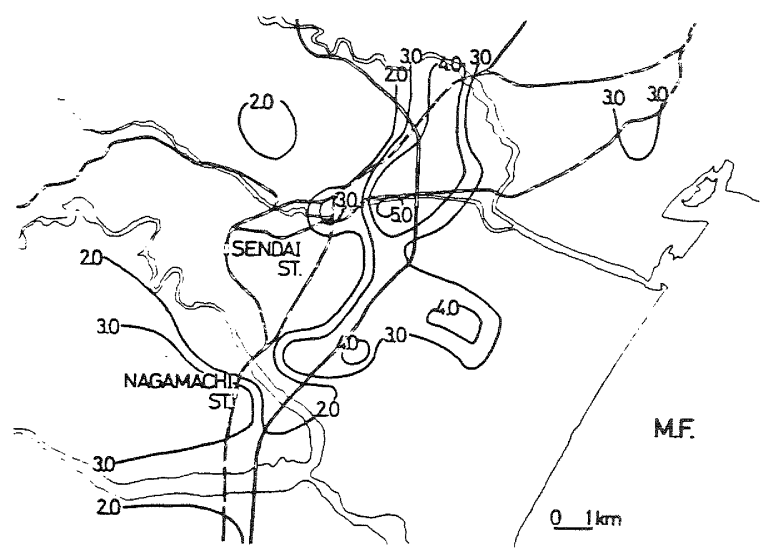

Fig。 14 Distribution Map of Magnification Factor
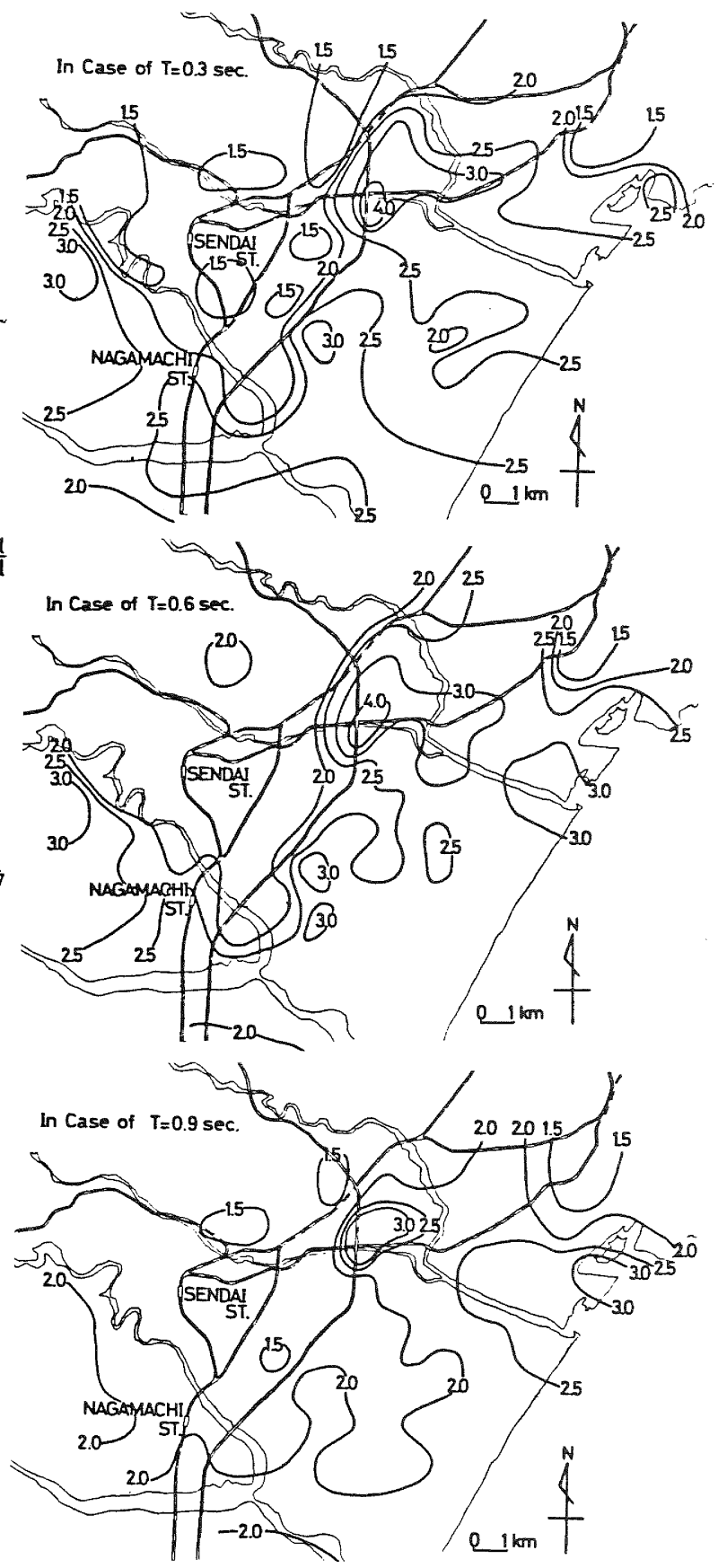

Fig. 16 Distribution Map of Ductility Factor 
alluvial plain. Similarly the magnification factor is about $2-3$ in the former and $3-5$ in the latter.

\section{Distribution of Maximum Acceleration and Vej.ocity -}

The maximum acceleration and velocities on the ground surface are caculated as the elastic response due to the incident wave on the structural base rock. The distribution maps of maximum acceleration and velocity are illustrated in Figs. $15(a)$ and (b), where the values of contour lines are normalized by the maximum value. seen in this figure, the value in the alluvial plain is about 1.5 times as large as that of the several levels of terraces.

\section{Distribution of Ductility Factor -}

The response of inelastic singledegree-of-freedom systems having degrading bilinear hysteresis when subjected to the motions on the ground surface obtained from the elastic response of soil-layer are computed. The distribution maps of the ductility factor of the super-structure, which is defined by the absolute maximum displacement normalized by the yield displacement, with the damping ratio (h) of 0.05 and the yielding base shear coefficient of 0.3 are shown in Figs. $16(a)-$ (c), where typical values are selected for the period of the system in the elastic range.

As recognized from these figures, the distribution pattern is not sensitive to the natural period of super-structures. As a rule, contour lines of ductility factors for shorter periods are similar to those of the maximum accelerations. As the period increases, these look like those of the maximum velocities.

COMPARISON OF DAMAGE TO BUILDINGS WITH MICROZONING MAPS:

Extent of Damage to Buildings:

Figure 17 shows the distribution of damage to reinforced concrete buildings, steel buildings, wooden houses and landslide areas in the sendai district. Severe damage to reinforced concrete and to steel structures were concentrated on the deluvium and on the alluvial plain respectively. Damage to wooden houses was on the alluvium and on several levels of terrace.

Three-storied reinforced concrete buildings were exhaustively damaged by shear failure of columns in the first storey (See photo. 1). Almost all damage to low-rise steel structures was brought about by buckling and breaking of bracings and failure of anchoring (See Photo. 2). The damage to wooden houses can be classified into two types (See Photo. 3); (1) damage due to ground motions on the alluvium plain and (2) damage due to landslide of embankment on the terrace.

Comparison of Distribution of Damage with Zoning Maps -

From the comparison of Fig. 17 with
Fig. 15 or Fig. 16, correlation between the location of severely damaged structures and the distribution of the maximum acceleration or of the ductility factor is generally good. It should be noted, however, that the soil is assumed to behave elastically in this analysis. In the case of severe earthquakes, this will be a crude approximation and should be modified.

Figure 18 illustrates the distribution of maximum acceleration obtained by the aforementioned inelastic analysis of soil-layers. It seems that the maximum accelerations tend to distribute more uniformly than those in Fig. 15. Figure 19 shows the horizontal distribution of the ductility factor of the super-structure due to motions on the ground surface, which are obtained from both the elastic and inelastic analyses of soil-layers on $A-A$ ' line indicated in Figs. 1 and 17.

As seen in this figure, the difference between the results of the analyses is smaller to the west of the Rifu-Nagamachi tectonic line, whereas larger to the east of this line. It is recognized that the ductility factors of the super-structures are higher especially in the inelastic analysis at Nigatake and Oroshimachi areas, which are situated around $\mathrm{E} 60$ indicated in the figure. This corresponds to the fact that damage of buildings are concentrated in this district.

\section{CONCLUDING REMARKS:}

The dynamic characteristics of underground-and-super structures in the Sendai district were investigated. The shallow ground characters were evaluated by microtremor measurements, boring data, penetration tests and so on. The incident wave motion was calculated by the aid of strong motion accelerograms recorded during the Off-Miyagi Prefecture Earthquake.

The predominant periods, magnification factors, maximum accelerations and velocities on the ground surface and the ductility factors of super-structures were computed. The real damage to buildings were compared with such microzoning maps. Close correlation between the both was recognized, especially when soillayers are assumed to behave inelastically. As for the results, it is pointed out that the analytical investigation presented herein is appropriate for the seismic microzoning maps.

\section{ACKNOWLEDGEMENTS :}

The authors would like to acknowledge the continuing encouragement of $\mathrm{Dr} \mathrm{M}$. Watabe, Director of International Institute of Seismology and Earthquake Engineering, Building Research Institute. In preparing the present paper, Mr M. Tohdo, Research Member of Toda Construction Co. Ltd, contributed a great deal. The authors also wish to express their sincere thanks to Dr Y. Sugimura, Head of Geotechnical Engineering Division, Building Research Institute, for his 
help with a large amount of geological data; and to Mr T. Kashima and Miss $\mathrm{K}$. Komatsuzaki, Members of the Building Research Institute and Miss M. Ota, Member of KKSK, for drawing the figures and typing the manuscript.

\section{REFERENCES :}

1) "Report on the Damage by 1978 Off-Miyagi Prefecture Earthquake (in Japanese)", Rept. of BRI, No. 86, pp. 75-81, 1979.

2) Y. Ohta and N. Goto, Empirical Shear Wave Velocity Equations in Terms of Characteristic Soil Indexes," EESD, Vol. 6, pp. 167-187, 1978 .

3) "Report on the Damage by 1978 Off-Miyagi Prefecture Earthquake (in Japanese)", Rept. of STA, No. 15, pp. 58-60, 1978 .

4) Y. Osawa, Y. Kitagawa and K. Ishida: "Response Analyses of Earthquake Motions Observed in and Around a Reinforced Concrete Building Including Building Sub-soil System", Proc. of 5WCEE, Rome, 1973.

5) J. Penzien and M. Watabe; "Characteristics of 3-Dimensional Earthquake Ground Motions", Earthquake Engineering and Structural Dynamics, 3 , pp. 365-373, 1975.

6) Y. Ohsaki, A. Hara and Y. Kiyota; "Stress-Strain Model of Soils for Seismic Analysis (in Japanese)", Proc. of 5WCEE, pp. 679-704, 1978.
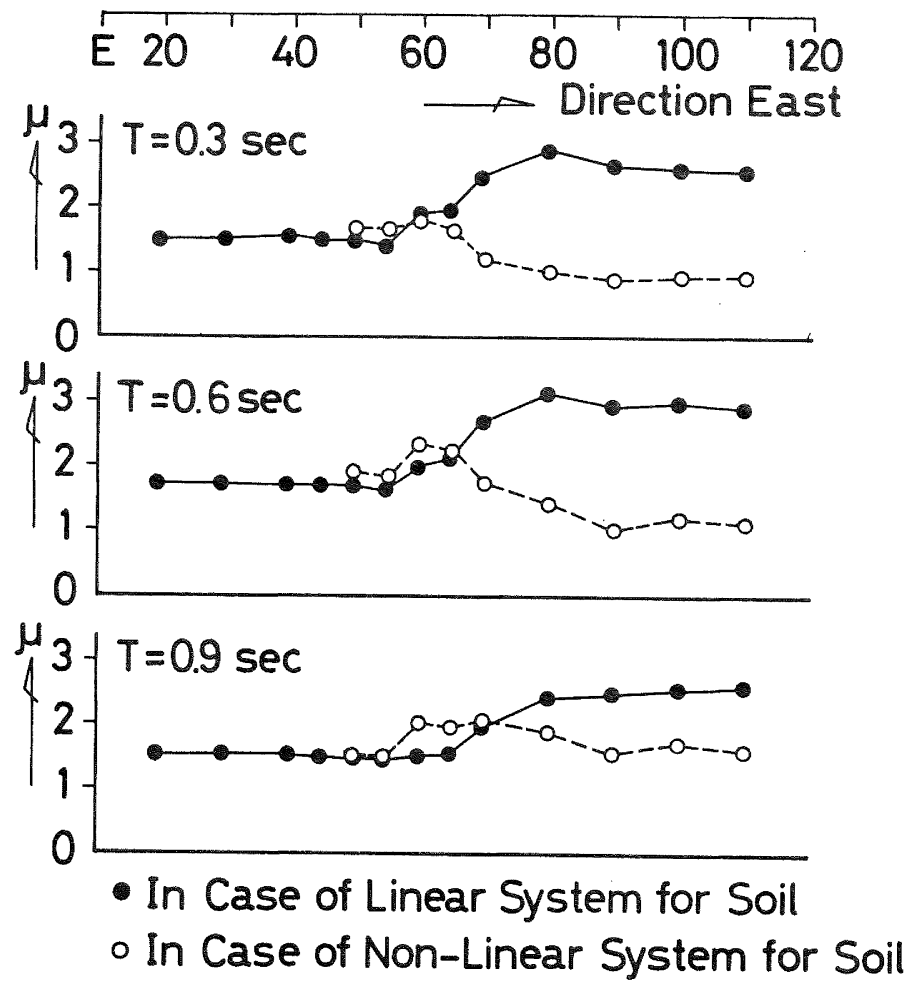

Fig. 19 Distribution Map of Ductility Factor

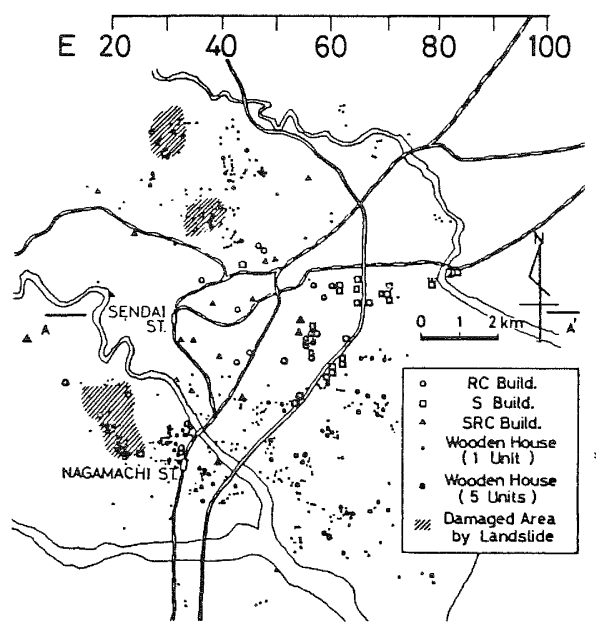

Fig。 17 Distribution Map of Damage

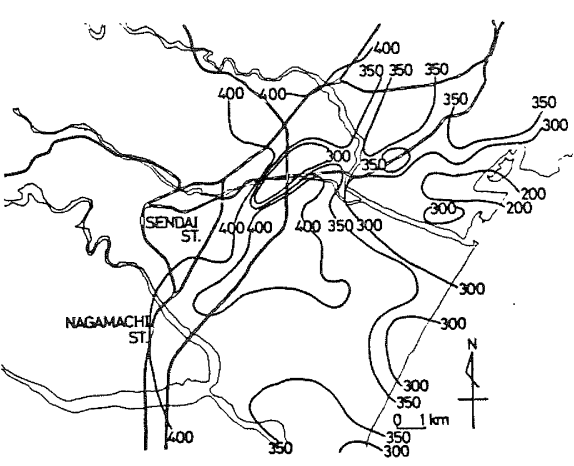

Fig. 18 Distribution Map of Max. Acceleration obtained by Inelastic Analysis of Soil-layers 

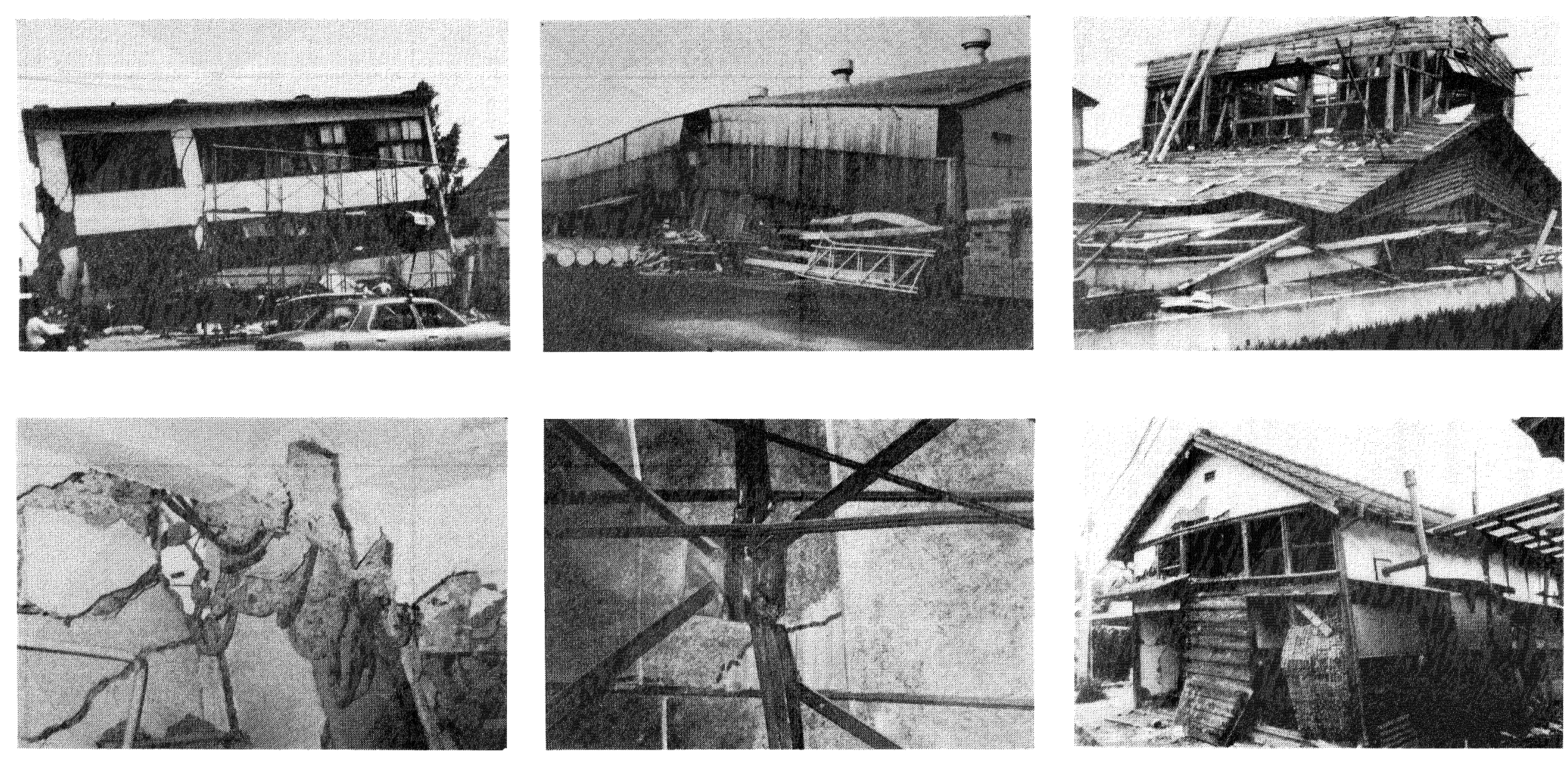

Photo. 1: Reinforced Concrete Building Damaged by Shear Failure of Column in First Story

Photo. 2: Low-rise Steel Structure Damaged by Buckling and Breaking of Bracing and Failure of Anchoring
Photo. 3: Wooden House Damaged by Ground Motions on Alluvium Plain 